\title{
Extractives From the Bark of Common Spruce, Picea abies L. Karst
}

\author{
TORBJ ÖRN NORIN and BJ ÖRNWINELL
}

Swedish Forest Products Research Laboratory, Box 5604, S-11486 Stockholm, Sweden

\begin{abstract}
The methylene chloride extract from the bark of common spruce, Picea abies L. Karst, has been investigated. It consists of free and esterified fatty acids $\left(\mathrm{C}_{12}-\mathrm{C}_{24}\right)$, resin acids of abietane and pimarane type, ferulic esters, $p$-hydroxycinnamic esters, fatty alcohols $\left(\mathrm{C}_{18}-\mathrm{C}_{28}\right)$, alkanes $\left(\mathrm{C}_{15}-\mathrm{C}_{38}\right), \beta$-sitosterol, campesterol, monoterpenes ( $p$-cymene, bormeol, and terpineol), sesquiterpenes ( $\alpha$-longipinene, longifolene, and $\gamma$-muurolene), diterpenes (methylesters of resin acids of abietane and pimarane type, abienol, manoyloxide, epimanoyloxide, pimaradiene, pimarol, dehydroabietol, and methyl 15-hydroxydehydroabietate), and triterpenes of serratene type $(3 \alpha$-methoxyserrat14-en-21 $\beta$-ol, $21 \alpha$-methoxyserrat-14-en-3-one, and $3 \beta$-methoxyserrat14-en-21 $\beta$-ol).
\end{abstract}

Picea abies L. Karst., common spruce or Norway spruce, is a native of Europe, where it has a very wide distribution. The bark of this forest tree is smooth and reddish-brown on young trees. Later it becomes a greyishbrown crust which peels off in round pieces. The morphology of the bark is complex and there is no definite distinction between inner and outer bark. However, most investigations, which so far have been published, have been carried out on the whole bark from the cambial region to the outer bark.

The bark is very rich in tannins. Grassman and Endres ${ }^{1}$ isolated piceatannol and its dihydro-derivative. This phenol also occurs in the plant as a monoglucoside and a diglucoside. Two monoglucoside derivatives of dihydropiceatannol and the flavanol quercetin and its glucoside were also found. The structure of piceatannol was challenged by Haworth et al., ${ }^{2}$ who isolated a compound apparently identical to piceatannol. Lindstedt and Zacharias ${ }^{3}$ studied the tannin extract by two-dimensional paper chromatography. A large number of components were detected. Kotasek and Langmaier ${ }^{4}$ investigated the water extract and detected fluorescent polyphenolic constituents and polyuronides. Sharkov ${ }^{5}$ investigated the bark and studied the water extract, ethyl alcohol extract, pectic substances, cellulose, uronic acids, pentosans, lignin, methoxyl content, fermentable sugars, and ash. A number of poly- 
hydroxyphenols and glycosides were recently isolated from the inner bark by Alcubilla ${ }^{6}$ in connection with an investigation of fungistatic bark constituents.

The lipophilic extractives have not been studied in detail. Andersson ${ }^{7}$ separated an ether extract into fractions (waxes, saponifiables, unsaponifiables fatty acids, resin acids, phenols, and other acids) according to their chemical properties in connection with an examination of the influence of bark on hardboard properties.

Large quantities of bark are obtained as a waste product from the pulp industry. The utilization of the bark is an important problem which so far has not been satisfactorily solved. ${ }^{8,9}$ Further fundamental knowledge of the chemistry of the bark is of importance for studies on bark utilization.

The aim of the present investigation was to make a careful examination of the lipophilic bark extractives from $P$. abies. Similar investigations have been performed on American Picea species $\left(P\right.$. glauca, ${ }^{10} P$. sitchensis, ${ }^{11-14} P$. jezoensis ${ }^{15}$ ) and also on various $P$ inus species. ${ }^{16}$ Chemotaxonomic considerations may therefore be possible.

\section{RESULTS AND DISCUSSION}

The methylene chloride extract was separated into light petroleum soluble and insoluble fractions. The fatty acids and hydroxy fatty acids which were detected after hydrolysis of the petroleum ether insoluble fraction are most probably constituents of the cork suberin. ${ }^{17}$

The light petroleum soluble fraction was further separated into an acid and a neutral fraction. The acid fraction consisted mainly of resin acids of the same type as has been found in the oleoresin. ${ }^{18,19}$ The fatty acids were not investigated in detail. The acid fraction also contained phenolic waxes. They were identified as fatty alcohol esters of ferulic acid and $p$-hydroxycinnamic acid.

The neutral part of the light petroleum soluble fraction was chromatographed on silica. The following types of constituents were isolated: hydrocarbons, waxes, sterols, triterpenes, higher alcohols, and oxygenated diterpenes.

The hydrocarbon fraction contained saturated and unsaturated compounds. The saturated hydrocarbons were alkanes $\left(\mathrm{C}_{15}-\mathrm{C}_{38}\right)$. It is interesting to note that the alkane composition differed noticeably from that of the bark of Scots pine (Pinus silvestris). ${ }^{16}$ Spruce bark has an alkane fraction with an almost equal distribution of odd and even numbered chains whereas in pine bark the odd numbered chains predominate. The unsaturated hydrocarbon fraction was found to contain a terpene mixture with similar composition ${ }^{19}$ to that of the wood and oleoresin.

The waxes were found to be esters of fatty acids $\left(\mathrm{C}_{12}-\mathrm{C}_{24}\right.$ with oleic and linolic acid as main components), sterols (mainly $\beta$-sitosterol), and fatty alcohols $\left(\mathrm{C}_{18}-\mathrm{C}_{26}\right)$.

The main part of the neutral fraction was a complex mixture of sterols ( $\beta$-sitosterol and campesterol), fatty alcohols $\left(\mathrm{C}_{18}-\mathrm{C}_{26}\right)$ and terpenoid alcohols (borneol, terpineol, pimarol, and dehydroabietol). 
Kutney and Rogers, ${ }^{12}$ Kutney et al. ${ }^{13}$ and Rogers and Rozon ${ }^{14}$ have previously isolated nine serratene derivatives from the bark of Picea sitchensis. Serratene derivatives have also been found in the bark of several Pinus species. ${ }^{16,20-22}$ In the bark of Picea abies we have identified $3 \alpha$-methoxyserrat-
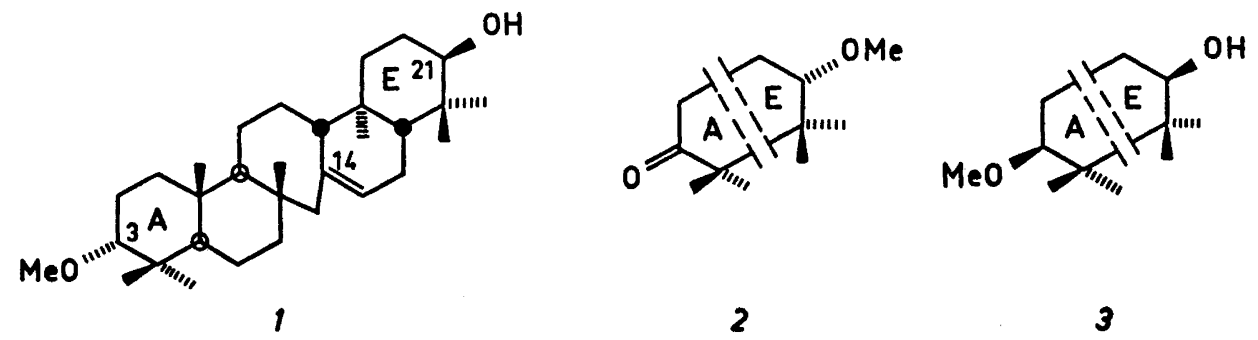

14-en-21 $\beta$-ol (1), $21 \alpha$-methoxyserrat-14-en-3-one (2), and $3 \beta$-methoxyserrat-14en-21 $\beta$-ol (3). The latter could not be isolated in a pure state but was identified by comparing its GLC and TLC properties with those of an authentic sample. $21 \alpha$-Methoxyserrat-14-en-3-one (2) is a new natural product. It was identified by analysis of its mass spectrum ${ }^{23}$ and of IR, NMR, and ORD data. The positive molecular amplitude $(+38.2)$ of its ORD spectrum strongly suggests a 3-keto function. ${ }^{24}$ Structure (2) was proved by reduction of the ketone and methylation of the alcohol thus obtained. The identity of the product, $3 \beta, 21 \alpha$-dimethoxyserrat-14-ene (serratenediol dimethyl ether) was shown by comparison with an authentic sample.

A part of the neutral fraction was found to be methyl esters of resin acids. Resin acid methyl esters do not commonly occur in Nature but have been detected in Cistus labdaniferus ${ }^{25}$ and also in the oleoresin from Norway spruce ${ }^{19}$ and Douglas fir. ${ }^{26}$ Other diterpenes, which were isolated from the neutral fraction, are manoyloxide, epimanoyloxide, and abienol. These constituents are also present in the oleoresin from $P$. abies. ${ }^{19}$

In addition to the diterpenes mentioned above a new natural product, methyl 15-hydroxydehydroabietate $(4 a)$, was isolated. The compound (m.p. $\left.75-77^{\circ}\right),[\alpha]_{\mathrm{D}}\left(\mathrm{CHCI}_{3}\right)+45.6^{\circ}$, was identified by an analysis of its spectroscopic properties (UV, IR, NMR, and MS) and by conversion to methyl dehydroabietate (6) via the corresponding styrene (5).

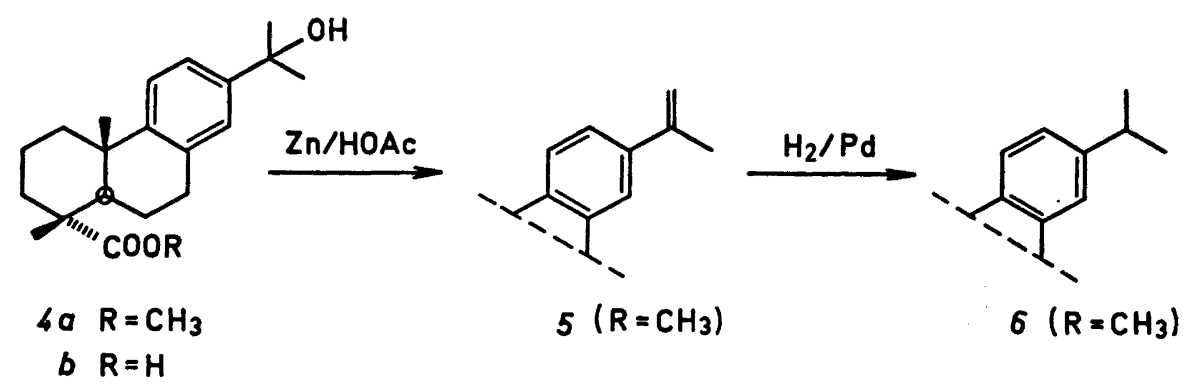

Acta Chem. Scand. 26 (1972) No. 6 
The MS of methyl 15-hydroxydehydroabietate exhibits significant peaks due to fragmentation of similar type to those reported ${ }^{27}$ for methyl dehydroabietate and other aromatic diterpene esters with a very strong $\mathrm{M}-75$ peak and less intense $\mathrm{M}-47$ and $\mathrm{M}-59$ peaks. Due to water extrusion methyl 15-hydroxydehydroabietate $(4 a)$ has an additional fragmentation pattern with peaks $312(\mathrm{M}-18), 265(\mathrm{M}-18-47), 253(\mathrm{M}-18-59)$, and 237 $(\mathrm{M}-18-75) \mathrm{m} / \mathrm{e}$.

The dehydration of methyl 15-hydroxydehydroabietate $(4 a)$ was performed with zinc in acetic acid. The product (5) thus obtained was crystalline (m.p. $65.5-68.5^{\circ}$ ). It had spectral properties (UV, IR, and NMR) similar to those previously reported. ${ }^{28,29}$ However, the melting point differs from that reported $\left(158-16 \mathrm{I}^{\circ}\right)$ by Banarjee et al. ${ }^{29}$ The MS of compound (5) was very similar to that of methyl dehydroabietate except that the characteristic peaks were two mass units lower (see Experimental).

After the completion of this work Carman and Marty ${ }^{28}$ reported the isolation of the corresponding hydroxy acid (4b) from Agathis species. This acid was characterized as its methyl ester $\left(4 a ;\right.$ m.p. $82-83^{\circ}, 90-91^{\circ}$ after sublimation; $\left.[\alpha]_{\mathrm{D}}(\mathrm{EtOH})+54^{\circ}\right)$ the properties of which are similar to those recorded by us.

The occurrence of norditerpenes of abietane and pimarane types in the bark of various Pinus species has been reported. ${ }^{30}$ Despite the fact that the bark of Picea abies is rich in diterpenes, we have not been able to detect any norditerpenes.

The possible chemotaxonomic significance of triterpenes of serratene type in bark of Pinus and Picea species is commented upon in a following paper. ${ }^{16}$

\section{EXPERIMENTAL}

Light petroleum refers to the fraction with the boiling range $40-60^{\circ}$. NMR spectra were, unless otherwise stated, recorded at $60 \mathrm{Mc} / \mathrm{s}$ (solvent, $\mathrm{CDCl}_{3}$ : internal standard, TMS).

Extraction. The air-dried bark $(5 \mathrm{~kg}$ ) was extracted with methylene chloride for one week. The bark was then dried and extracted with acetone for one week. Removal of the solvents gave $175 \mathrm{~g}(3.5 \%)$ of methylene chloride soluble extract and $197 \mathrm{~g} \mathrm{(3.9 \% )}$ of acetone soluble extract. The acetone soluble part has not been investigated.

The methylene chloride soluble part was soaked with light petroleum. The light petroleum insoluble fraction $(22 \mathrm{~g})$ was a yellow powder. Some $(2 \mathrm{~g})$ of this material was saponified $(20 \% \mathrm{w} / \mathrm{v}$ of $\mathrm{KOH}$ in aqueous methanol, $5 \mathrm{~h})$. The hydrolysate was diluted with water and extracted with several portions of ether. The ether extract $(0.2 \mathrm{~g})$ was found to consist mainly of fatty alcohols $\left(n-C_{18}-n-C_{24}\right)$. The alkaline part was acidified and taken up in ether. The GLC-analysis (1\% XE 60) of this ether extract showed the presence of the following compounds: $9 \%$ saturated fatty acids $\left(n-C_{20}-n-C_{24}\right)$ and $4 \%$ saturated hydroxy fatty acids $\left(n-C_{20}-n-C_{24}\right)$.

A part $(53 \mathrm{~g})$ of the light petroleum soluble fraction (153 $\mathrm{g}$ ) was separated in the usual way into a neutral fraction $(19.3 \mathrm{~g})$ and an acidic fraction $(33.3 \mathrm{~g})$.

\section{Neutral fraction}

The neutral fraction was separated on a silica column with increasing concentrations of ether in light petroleum. The separation was followed by TLC and the fractions were combined in a suitable manner. 
Fraction $1(1.0 \mathrm{~g})$ consisted of hydrocarbons. They were separated into saturated and unsaturated fractions by column chromatography on silver nitrate impregnated silica with light petroleum as eluent. The saturated fraction $(0.35 \mathrm{~g})$ consisted of alkanes which were analysed by GLC (1\% SE 30) and shown to be a complex mixture of mostly n-alkanes with the following composition: $\mathrm{C}_{16}-\mathrm{C}_{22}$ and $\mathrm{C}_{35}, 1 \%$ or less; $\mathrm{C}_{31}-\mathrm{C}_{84}, 1-3 \%$; $\mathrm{C}_{23}, \mathrm{C}_{24}, \mathrm{C}_{28}, \mathrm{C}_{29}$, and $\mathrm{C}_{30}, 5-8 \% ; \mathrm{C}_{27}, 12 \% ; \mathrm{C}_{26}, 14 \% ; \mathrm{C}_{25}, 17 \%$. There were also traces of $\mathrm{C}_{38}-\mathrm{C}_{38}$ and branched alkanes of all the above numbers of carbons. The unsaturated fraction $(0.59 \mathrm{~g})$ was a complex mixture of mono-, sesqui- and diterpenes. They were analysed by GLC (two different columns, $4 \%$ Carbowax and $1 \%$ XE 60). The following compounds were identified by comparison of retention data with those of authentic samples: $p$-cymene, $\alpha$-longipinene, longifolene (main compound), $\gamma$-muurolene, and pimaradiene.

Fraction $2(2.89 \mathrm{~g})$ was further fractionated (fractions $2.1-2.5$ ) on a silica column with light petroleum and benzene as eluents.

Fraction $2.1(0.54 \mathrm{~g})$ consisted of alkanes of similar composition as that of fraction 1.

Fraction $2.2(1.44 \mathrm{~g})$ exhibited a characteristic IR band at $1740 \mathrm{~cm}^{-1}$ (ester). A part of the fraction $(210 \mathrm{mg})$ was saponified with alkaline methanol under nitrogen for $5 \mathrm{~h}$ yielding unsaponifiable material $(130 \mathrm{mg}$ ) and an acid fraction $(80 \mathrm{mg})$. The unsaponifiable fraction was separated into a sterol fraction $(106 \mathrm{mg})$ and a fatty alcohol fraction (24 $\mathrm{mg}$ ) by preparative TLC ( $\mathrm{SiO}_{2} /$ light petroleum:ether, 1:1). The sterol and alcohol mixtures were analysed separately as their TMS derivatives by GLC ( $1 \%$ XE 60). The sterol mixture consisted of $\beta$-sitosterol $(90 \%)$ and campesterol $(10 \%)$. The alcohols were identified as n-aliphatio alcohols $\left(\mathrm{C}_{18}, 32 \% ; \mathrm{C}_{20}, 7 \% ; \mathrm{C}_{22}, 38 \% ; \mathrm{C}_{24}, 18 \% ; \mathrm{C}_{20}\right.$ $5 \%$ ). The acid fraction was analysed after esterification (ethereal diazomethane) by GLC (5\% BDS) and by TLC (silver nitrate impregnated silica). The fraction was found to consist of fatty acids $\left(\mathrm{C}_{12}-\mathrm{C}_{24}\right)$ with linolic acid $(54 \%)$ as main component.

Fraction $2.3(720 \mathrm{mg})$ was fractionated by preparative TLC (silver nitrate impregnated silica, benzene). Methyl dehydroabietate $(605 \mathrm{mg})$, methyl pimarate (12 $\mathrm{mg})$, methyl isopimarate $(45 \mathrm{mg})$, and methyl sandaracopimarate $(50 \mathrm{mg})$ were identified by comparison of chromatographic and spectral data (TLC, GLC, IR, MS and NMR) with those of authentic samples.

Fraction $2.4(120 \mathrm{mg})$ was fractionated by preparative TLC (silver nitrate impregnated silica, benzene). Two main constituents could be isolated and were found to be manoyloxide (36 mg; $[\alpha]_{\mathrm{D}}+22^{\circ}$, c 0.9 in $\mathrm{CHCl}_{3}$ ) and 13-epimanoyloxide (54 mg; m.p. 97-99 $[\alpha]_{\mathrm{D}}+37^{\circ}, c 0.2$ in $\mathrm{CHCl}_{3}$ ) by comparison of chromatographic and spectral data (TLC, GLC, IR, MS, and NMR) with those of authentic samples. Fraction 2.4 also contained small amounts $(8 \mathrm{mg})$ of methyl dehydroabietate.

Fraction 2.5 (50 mg) was a complex mixture (TLC, silver nitrate impregnated silica). Its IR spectrum exhibited characteristic ester bands at 1740 and $1250 \mathrm{~cm}^{-1}$. A singlet at $7.45 \tau$ in its NMR spectrum indicated the presence of acetate groupings.

Fraction $3(2.35 \mathrm{~g})$ was chromatographed on a silica gel column with ether $(15 \%)$ in light petroleum as eluent. Three fractions were collected $(3.1-3.3)$.

Fraction $3.1(1.81 \mathrm{~g})$ was fractionated by preparative TLC (SiO $/$ /benzene) yielding one main fraction, which exhibited a characteristic IR band at $1740 \mathrm{~cm}^{-1}$ (ester). A part of the fraction $(70 \mathrm{mg}$ ) was saponified with methanolic potassium hydroxide under nitrogen for $5 \mathrm{~h}$ and gave an acid fraction $(50 \mathrm{mg})$ and an unsaponifiable part $(20 \mathrm{mg})$. The acid fraction was found (TLC, GLC) to consist of fatty acids $\left(\mathrm{C}_{12}-\mathrm{C}_{22}\right)$ with oleic $(38.5 \%$ ) and linolic acid $(16.5 \%)$ as main components. The unsaponifiable part consisted of fatty alcohols, $\beta$-sitosterol and campesterol of similar composition as the unsaponifiable part of the waxes from fraction 2.2 as shown by TLC and GLC.

Fraction $3.2(291 \mathrm{mg})$ was found to be a complex mixture and was not further investigated.

Fraction $3.3\left(215 \mathrm{mg},[\alpha]_{\mathrm{D}}+19^{\circ}, c 0.2 \mathrm{in} \mathrm{CHCl}_{3}\right)$ was identified as abienol by a direct comparison of chromatographic and spectroscopic data (TLC, GLC, MS, IR, and NMR) with those of an authentic sample.

Fraction $4(2.93 \mathrm{~g})$ was dissolved in ether whereby a white insoluble precipitate could be filtered off ( $200 \mathrm{mg})$. The constituents of the precipitate were separated by preparative TLC $\left(\mathrm{SiO}_{2} / \mathrm{CHCl}_{3}\right.$ ) to yield a mixture of fatty alcohols and two triterpenes. The fatty alcohols $(70 \mathrm{mg}$ ) were analysed as TMS-derivatives by GLC (1 \% XE 60, 185 $)$. Three alcohols were detected: $n-C_{22}(13 \%), n-C_{24}(44 \%)$, and $n-C_{2 b}(43 \%)$. One of the triterpenes

Acta Chem. Scand. 26 (1972) No. 6 
(40 mg) was identified as $3 \alpha$-methoxyserrat-14-en-21 $\beta$-ol (1) by comparison (TLC, GLC, m.p., IR, NMR, and MS) with an authentic sample. ${ }^{12}$ The GLC analysis was performed on a $1 \% \mathrm{XE} 60$ column at $240^{\circ}$. The second triterpene (23 mg; m.p. 222.5 - 224 $4^{\circ}$, evacuated capillary; $[\alpha]_{\mathrm{D}}+8^{\circ}, c 0.2$ in $\mathrm{CHCl}_{3}$ ) exhibited the following characteristic spectral properties: IR $\left(\mathrm{cm}^{-1}, \mathrm{CCl}_{4}\right): 1701(>\mathrm{C}=\mathrm{O}), 1100\left(-\mathrm{O}-\mathrm{CH}_{3}\right)$. NMR (recorded at 100 $\mathrm{Mc} / \mathrm{s}, \tau$-units): 4.63 (1H, unresolved multiplet, olefinic proton); 6.64 (3H, singlet, $\mathrm{O}-\mathrm{CH}_{3}$ ); $7.54\left(1 \mathrm{H}\right.$, quartet, $J_{1}=8 \mathrm{cps}, J_{2}=6 \mathrm{cps}$, axial proton geminal to methoxyl); 8.9-9.3 $\left(21 \mathrm{H}\right.$, singlets, 7 angular methyl groups). MS: $\mathrm{M}^{+} 454,234,205$. ORD: $(\mathrm{MeOH}):[\phi]_{304}+$ $2850,[\phi]_{270}-900,[\phi]_{258}-970,[\phi]_{244}-240,[\phi]_{237}-2480, a+38.2$. These spectral data are in agreement with those expected for $21 \alpha$-methoxyserrat-14-en-3-one (2). The ketone (2) was reduced with lithium tri-t-butoxyaluminium hydride and the equatorial alcohol ${ }^{31}$ (main product) thus obtained was methylated with methyl iodide and potassium $t$ butoxide in toluene. The resulting product was shown to be $3 \beta, 21 \alpha$-dimethoxyserrat14-ene (serratenediol dimethyl ether) by comparison with an authentic sample (TLC, GLC, m.p., mixed m.p., IR, and MS).

The mother liquor (2.7 g) from the precipitation of the above compounds was found to be a complex mixture. 3 $\alpha$-Methoxyserrat-14-en-21 $\beta$-ol (1), 21 $\alpha$-methoxyserrat-14-en3 -one $(2)$, and fatty alcohols were detected in this mixture by TLC and GLC.

Fraction $5(1.06 \mathrm{~g})$ was dissolved in ether. A white insoluble fraction could be filtered off $(320 \mathrm{mg})$. The precipitate was a complex mixture. $3 \beta$-Methoxyserrat-14-en-21 $\beta$-ol (3) was detected (TLC and GLC) as the main component. The mother liquor was further fractionated on a silica column with $30 \%$ ether in light petroleum as eluent. The following compounds could be detected (GLC and TLC): borneol, terpineol, pimarol, dehydroabietol, $3 \beta$-methoxyserrat-14-en-21 $\beta$-ol (3), campesterol, $\beta$-sitosterol, and fatty alcohols.

Fraction $6(5.05 \mathrm{~g})$ was separated on a silica column with ether $(30 \%)$ in light petroleum as eluent. Three fractions were collected. The first fraction (1.6 $\mathrm{g})$ was shown by TLC and GLC to have a similar composition to that of fraction 5 . The second fraction $(2.2 \mathrm{~g})$ was found (TLC and GLC) to be a sterol mixture (campesterol and $\beta$-sitosterol). From the third fraction $(1.2 \mathrm{~g})$ a crystalline compound (m.p. $\left.75-77^{\circ}\right)$ could be isolated by repeated chromatography. The compound exhibited the following characteristic properties. $[\alpha]_{\mathrm{D}}+45.6^{\circ}\left(\mathrm{c} 0.4\right.$ in $\left.\mathrm{CHCl}_{3}\right)$. IR $\left(\mathrm{cm}^{-1}, \mathrm{CCl}_{4}\right): 3610(\mathrm{OH}) ; 1730$ (ester); 1500 , 910 (aromatic double bonds). NMR $(\tau): 2.80-2.85$ (3H, multiplet, aromatic protons); 6.37 (3H, singlet, methyl ester; 7.10 (2H, quartet, benzylic protons); 8.48 (6H, singlet, two methyl groups geminal to a hydroxyl group); 8.74, 8.81 (6H, 2 singlets, 2 angular methyl groups). UV: similar to that of dehydroabietic acid. ${ }^{\mathbf{3 2}} \mathbf{M S}: \mathbf{M}^{+} \mathbf{3 3 0 ,} 315(100 \%)$, $312,297,283,273,271,265,255(97 \%), 253$, and 237. (Found: $\mathrm{C} 76.0 \% ; \mathrm{H} \mathrm{9.3 \%}$. $\mathrm{C}_{21} \mathrm{H}_{30} \mathrm{O}_{3}$ requires $\mathrm{C} 76.3 \% ; \mathrm{H} 9.2 \%$ ). The properties of this compound are in agreement with those expected for methyl 15-hydroxydehydroabietate (4a).

Dehydration of methyl 15-hydroxydehydroabietate $(4 a)$ was perfomed according to a method previously reported ${ }^{33}$ by treating the hydroxy ester (13 $\left.\mathrm{mg}\right)$ with zinc in acetic acid. The product ( $5 \mathrm{mg}, \mathrm{m} . \mathrm{p} .65 .5-68.5^{\circ}$ ) exhibited the following characteristic spectral properties. IR $\left(\mathrm{cm}^{-1}, \mathrm{CCl}_{4}\right): 3080,1630\left(>\mathrm{C}=\mathrm{CH}_{2}\right) ; 1730$ (ester). NMR $(\tau)$ : $2.80-2.90$ (3H, multiplet, aromatic protons); 4.72, $5.01\left(2 \mathrm{H}\right.$, multiplets, $\left.>\mathrm{C}=\mathrm{CH}_{2}\right)$; 6.37 (3H, singlet, methyl ester); 7.15 (2H, multiplet, benzylic protons); 7.90 ( $3 \mathrm{H}$, doublet, $J=1 \mathrm{cps},-\mathrm{CH}_{3}$ in isopropylene group); $8.74,8.81$ (6H, 2 singlets, 2 angular methyl groups). UV: (nm) $\lambda_{\max }(\mathrm{EtOH}) 211(\log \varepsilon 3.64), 248(\log \varepsilon 4.35)$. MS: $\mathbf{M}^{+} 312,297$, $265,253,237(100 \%)$. The spectral properties of the product are consistent with those expected for methyl abieta-8,11,13,15-tetraen-18-oate (5).

Catalytic hydrogenation of compound (5) over palladium on charcoal in ethanol gave methyl dehydroabietate $(6)$, the identity of which was proved by a direct comparison of chromatographic and spectral data (TLC, GLC, MS, IR, and NMR) with those of an authentic sample.

The rest of the neutral fraction $(4.0 \mathrm{~g})$ was not investigated.

\section{Acidic fraction}

This fraction mainly consisted of resin acids. They were analysed as methyl esters by TLC and GLC. ${ }^{34}$ The following acids were identified: sandaracopimaric $(8 \%)$, 
levopimaric/palustric (35\%), dehydroabietic $(38 \%)$, abietic $(13 \%)$, and neoabietic acid $(6 \%)$.

Two phenolic fractions were isolated from the crude acid fraction by preparative TLC $\left(\mathrm{SiO}_{2}, 5 \% \mathrm{MeOH}\right.$ in $\left.\mathrm{CHCl}_{3}\right)$. One of the fractions exhibited spectral properties similar to those reported ${ }^{35}$ for a ferulic ester fraction. Saponification of the fraction gave ferulic acid and a mixture of fatty alcohols $\left(\mathrm{n}-\mathrm{C}_{20}, 7 \% ; \mathrm{n}-\mathrm{C}_{22} 57 \%\right.$; $-\mathrm{C}_{23}, 3 \%$; $n-\mathrm{C}_{24}, 33 \%$ ).

The second phenolic fraction had the following spectral properties: IR $\left(\mathrm{cm}^{-1}, \mathrm{NaCl}\right)$ : $3380(\mathrm{OH}) ; 3020,1600,1580,1510,860$, and 830 (aromatic double bonds); 1670 (unsaturated ester); 1630 (olefinic double bond). NMR ( $\tau): 2.50$ ( $1 \mathrm{H}$, doublet, $J=16 \mathrm{cps}$, olefinic proton); $2.70(2 \mathrm{H}$, doublet, $J=9.5 \mathrm{cps}$, aromatic protons); $3.27(2 \mathrm{H}$, doublet, $J=9.5$ cps, aromatic protons); 3.86 ( $1 \mathrm{H}$, doublet, $J=16 \mathrm{cps}$, olefinic proton); 5.90 (2H, badly defined quartet, $\left.\mathrm{R}-\mathrm{CH}_{2}-\mathrm{O}-\mathrm{C}(\mathrm{O})-\right) ; 8.76\left(\sim 40 \mathrm{H}\right.$, singlet, $\left.-\left(\mathrm{CH}_{2}\right)_{\mathrm{n}}-\right) ; 9.15(3 \mathrm{H}$, triplet, $\left.\mathrm{CH}_{3}-\right)$. These data suggest that the product is a mixture of esters of fatty alcohols and $p$-hydroxycinnamic acid. The: observed coupling constant $(J=16 \mathrm{cps})$ for the signals of the olefinic protons indicates a trans-configuration of the cinnamic acid double bond. Hydrolysis of the esters yielded $p$-hydroxycinnamic acid and a mixture of fatty alcohols (n-C $\left.18,4 \% ; n-C_{20}, 7 \% ; n-C_{22}, 45 \% ; n-C_{24}, 44 \%\right)$.

Acknowledgements. The authors wish to thank Dr. J. W. Rowe and Dr. I. H. Rogers for gifts of serratene derivatives. We are grateful to Professor W. Klyne for the ORD measurements. The assistance by Mr. Birger Ericsson in the investigation of the light petroleum insoluble fraction of the bark extract is acknowledged.

\section{REFERENCES}

1. Grassman, W. and Endres, H. Ber. 89 (1956) 2523; 91 (1958) 134.

2. Cunningham, J., Haslam, E. and Haworth, R. D. J. Chem. Soc. 19632875.

3. Lindstedt, G. and Zacharias, B. Acta Chem. Scand. 9 (1955) 781.

4. Kotasek, Z. and Langmaier, F. Veda Vyzkum Prumyslu Kozedelnem 4 (1958) 5; Chem. Abstr. 53 (1959) 19045.

5. Sharkov, V. I. Gidrolizn. $i$ Lesokhim. Prom. 8 (1955) Nos. 7 and 3; Chem. Abstr. 50 (1956) 4498.

6. Alcubilla, M. Z. Pflanzenernähr. Düng. Bodenk. 127 (1970) 64.

7. Andersson, A. B. Norsk Skogsind. 11 (1957) 386.

8. Bender, F. Can. Dep. Forest. Publ. No. 1248 (1968).

9. Eriksson, K. E., Larsson, K., Norin, T. and Winell, B. Svensk Papperstid. 74 (1971) 685.

10. Bishop, C. T., Harwood, V. D. and Purves, C. B. Pulp Paper Mag. Can. 51 (1950) 90.

11. Kohlbrenner, P. J. and Schuerch, C. J. Org. Chem. 24 (1959) 166.

12. Kutney, J. P. and Rogers, I. H. Tetrahedron Letters 1968761.

13. Kutney, J. P., Rogers, I. H. and Rowe, J. W. Tetrahedron 25 (1969) 3731.

14. Rogers, I. H. and Rozon, L. R. Can. J. Chem. 48 (1970) 1021.

15. Hata, K. and Sogo, M., Kagawa Daigaku Nogakubu Gakuzyuta Hokoku 11 (1959) 270; Chem. Abstr. 54 (1960) 10316.

16. Norin, T. and Winell, B. Acta Chem. Scand. 26 (1972) 2297.

17. Kurth, E. F. Tappi 50 (1967) 253.

18. Bruun, H. H. and Gåsland, S. Abo Akademi Meddelande 1960, No. 185.

19. Kimland, B. and Norin, T. Svensk Papperstid. In press.

20. Rowe, J. W. Tetrahedron Letters 19642347.

21. Rowe, J. W. and Bower, C. L. Tetrahedron Letters 19652745.

22. Bower, C. L. and Rowe, J. W. Phytochemistry 6 (1967) 151.

23. Kutney, J. P., Eigendorf, G. and Rogers, I. H. Tetrahedron 25 (1969) 3753.

24. Tsuda, Y., Sano, T., Kawaguchi, K. and Inubushi, Y. Tetrahedron Letters 19641279.

25. Tabacik-Wlotzka, C. Bull. Soc. Chim. France 1964618.

26. Erdtman, H., Kimland, B., Norin, T. and Daniels, P. J. L. Acta Chem. Scand. 22 (1968) 938.

27. Enzell, C. R. and Wahlberg, I. Acta Chem. Scand. 23 (1969) 871.

28. Carman, R. M. and Marty, R. A. Australian. J. Chem. 23 (1970) 1457.

Acta Chem. Scand. 26 (1972) No. 6 
29. Banarjee, D. K., Sukh Dev, Kasturi, T. R. and Raghavan, E. Indian J. Chem. 6 (1968) 409.

30. Norin, T. and Winell, B. Acta Chem. Scand. 25 (1971) 611.

31. Wheeler, O. H. and Mateos, J. L. Can. J. Chem. 36 (1958) 1431.

32. Fieser, L. F. and Campbell, W. P. J. Am. Chem. Soc. 60 (1938) 159.

33. Quilico, A., Panizzi, L. and Mugnaini, E. Gazz. Chim. Ital. 79 (1949) 89.

34. Norin, T. and Westfelt, L. Acta Chem. Scand. 17 (1963) 1828.

35. Rowe, J. W., Bower, C. L. and Wagner, E. R. Phytochemistry 8 (1969) 235.

Received November 4, 1971. 